\title{
CONSTRUINDO O SINDICALISMO TRANSNACIONAL: O CASO DOS TRABALHADORES NA JOHNSON CONTROLS DO MÉXICO (PLANTAS FINSA E INTERIORES) $^{(*)}$
}

\author{
BUILDING TRANSNATIONAL UNIONISM: THE WORKERS IN JOHNSON CONTROLS \\ CASE (FINSA AND INTERIORES PRODUCTION PLANTS)
}

Katiuscia Moreno Galhera Espósito ${ }^{(* *)}$

\begin{abstract}
Resumo: Uma das estratégias dos sindicatos, diante da queda geral dos níveis de sindicalização e a constante desregulamentação do trabalho, é a atuação em nível transnacional, por meio de redes de informação, comunicação e mobilização globais. O objetivo do presente artigo é analisar uma dessas redes.Especificamente, a internacionalização da campanha de trabalhadores em duas maquilas estadunidenses e o papel da Federação Internacional dos Trabalhadores das Indústrias Metalúrgicas (FITIM). O exame será realizado a partir de fontes primárias como: entrevistas com militantes e especialistas, notícias de jornais, acordos etc. Ao final esperamos demonstrar a ação das redes internacionais de sindicatos e seus resultados.
\end{abstract}

Palavras-chave: Globalização; Sindicalismo transnacional; Redes de informação; Federação Internacional dos Trabalhadores da Indústria Metalúrgica (FITIM).

Abstract: One of the strategies of unions, to fight against the overall decline in levels of unionization and the constant labor deregulation, is acting transnationally through information networks, global communication and mobilization. The aim of this paper is to analyze one of these networks. Specifically, the analysis is on the internationalization of the campaign of workers in two U.S. maquilas and on the role of the International Metalworkers' Federation (IMF). The exam will be held from primary sources such as interviews with experts and activists, newspaper reports, agreements and so son. At the end we hope to demonstrate the action of the international networks of trade unions and their results.

Keywords: Globalization; Transnational unionism; Information networks; International Metalworkers' Federation (IMF).

\footnotetext{
(*) O artigo esá baseado a dissertação de mestrado, intitulada "Transnacionalização das relações de trabalho: o caso da maquila estadunidense Johnson Controls (planta FINSA e Interiores) e o papel da Federação Internacional de Trabalhadores das Indústrias Metalúrgicas (Fitim)", defendida pela autora em 2012 junto ao Programa San Tiago Dantas de Pós-Graduação em Relações Internacionais (PUC-SP/Unesp/Unicamp).

$(* *)$ Doutoranda em Ciência Política (UNICAMP). Mestre em Relações Internacionais (PPGRI San Tiago Dantas). E-mail: <kgalhera@yahoo.com.br>. Recebido em 17.05.2013 e aceito em 10.06.2013.
} 


\section{INTRODUÇÃO}

As questões relacionadas ao mundo do trabalho são temas debatidos não apenas na Academia, mas também por diversos grupos políticos e sociais no bojo das sociedades.

As bases de atuação nacional dos movimentos operários foram em parte erodidas - notadamente nos países de industrialização avançada - sobretudo pela internacionalização das empresas na era "pós-fordista" [COX, 1996 (1991)] ou da "acumulação flexível" [HARVEY, 2007 (1989)], intensificada a partir da década de 1970, que trouxe como consequência uma nova configuração mundial da produção, aprofundando a divisão internacional do trabalho já existente.

Se as empresas multinacionais possuem estratégias de internacionalização da produção, existem casos em que as estratégias dos sindicatos no mesmo âmbito trouxeram benefícios aos trabalhadores, como na construção de redes sindicais na empresa brasileira Gerdau a partir dos Estados Unidos ${ }^{(1)}$.

Outros exemplos se relacionam com as ações das Federações Sindicais Internacionais (FSIs) ou Global Union Federations (GUFs). Especificamente, versaremos sobre a atuação de nosso objeto de estudo, a Federação Internacional de Trabalhadores das Indústrias Metalúrgicas (FITIM) ${ }^{(2)}$, uma FSI do ramo metalúrgico, na campanha promovida em benefício dos trabalhadores da maquila ${ }^{(3)}$ estadunidense de fabricação de autopeças, a Johnson Controls (JC). Partimos da hipótese de que as organizações sindicais e as instituições e fóruns internacionais, apesar de não possuírem os mesmos instrumentos de poder dos Estados, são capazes de constranger e influenciar outros atores (nesse caso, as empresas multinacionais e o Estado mexicano) para fazê-los alterar seu comportamento na relação entre capital e trabalho a favor dos trabalhadores. No entanto, e conforme já foi demonstrado por outros pesquisadores, a grande mobilidade relativa do capital, se comparada à localidade e estagnação do trabalho, apresenta uma força muito maior, e decisiva, no eterno embate entre capital e trabalho (CASTELLS, 1999, p. 476; VIGEVANI, 1998, p. 334; WATERMAN apud SANTOS, 2005, p. 93). Para a elaboração deste trabalho utilizamos de fontes primárias, como reclamações junto à OIT e entrevistas.

\section{CONSTRUINDO O SINDICALISMO TRANSNACIONAL: ANTECEDENTES}

Os sindicatos nacionais no México enfrentam inúmeros problemas relacionados ao sindicalismo cooptado pelo Estado — ou corporativista — e às leis, que dificultam a ação de sindicatos independentes. Ao apontar que existem casos em que a construção de redes sindicais internacionais - ou transnacionalismo sindical — obteve êxito, pretendemos sugerir que essa pode ser uma opção ao tradicional sindicalismo local.

(1) Ver: GRAY, Chad. Metalúrgicos sem fronteiras: Building a Global Union at GERDAU. 2009. 177 p. Dissertação (Master of Science). Universidade de Cornell, Ithaca, 2009

(2) AFITIM é uma associação de sindicatos nacionais que opera transnacionalmente.

(3) A região da maquila funciona como zona franca, sem qualquer conexão com a cadeia produtiva do parque industrial mexicano (GORENDER, 1997, p. 339-340). 
Nossa intenção neste artigo é assinalar os êxitos e malogros do sindicalismo transnacional construído a partir de suas plantas específicas: FINSA e Interiores. A JC fornecia peças para a Daimler/Mercedes-Benz, BMW, Chrysler/Fiat, Nissan, Volkswagen e Ford, sendo que pelo menos quatro Acordos Marco Internacionais (AMIs) ${ }^{(4)}$ foram assinados com a FITIM e poderiam ter sido utilizados em favor dos trabalhadores, mesmo com as desvantajosas características da legislação mexicana.

AJC é uma multinacional de matriz norte-americana baseada em Milwaukee, Wisconsin (WI). Possui aproximadamente 90 subsidiárias, tem participação direta ou indireta em mais de 125 países, dentre eles Brasil, China e México, e emprega mais de 140 mil pessoas em todo o mundo (JOHNSON CONTROLS, 2011, s. p.).

À época deste estudo (2012), a empresa contava com mais de 30 sucursais no México (distribuídas entre head quartes/administradoras, unidades comerciais, residenciais ou produtivas), sendo que 13 eram plantas produtivas, localizadas em Ciudad Juarez (três unidades); Ramos Arizpe e Lerma (duas unidades em cada); Monclova, Saltillo, Puebla, Tlaxcala, Matamoros e Reynosa (uma unidade em cada cidade) (JOHNSON CONTROLS, 2012 , s. p.). Neste trabalho, versamos sobre duas plantas: a FINSA (localizada em Puebla) e a Interiores (localizada em Tlaxcala). Ambas podem ser caracterizadas como maquiladoras.

\subsection{A SITUAÇÃO DOS TRABALHADORES}

Parte da força de trabalho da planta era subcontratada por diversas empresas terceirizadas, sendo que a empresa One Digit era a que fornecia mão de obra com maior frequência para a JC (FITIM, 2009a, p. 24; UNITED AUTO WORKERS et al., 2010, p. 2). Podemos afirmar que a condição dos trabalhadores da One Digit na JC é um caso de subcontratação da quarteirização, já que a JC é uma terceirizada das grandes montadoras, que, por sua vez, subcontrata empregados de outras terceirizadas, dentre elas a One Digit.

Os trabalhadores da JC no México muitas vezes tiveram seus direitos desrespeitados, com frequência, em descumprimento aos direitos fundamentais previstos pela OIT, como discriminação de gênero (diferença salarial, câmeras nos armários das mulheres, assédio sexual, constrangimento e demissão de grávidas); más condições de trabalho; horas extras e descontos do seguro de saúde abusivos; falta de representação sindical de fato; contratos individuais em detrimento dos contratos coletivos (em sua maioria, temporários); e diminuição progressiva até a eliminação de bônus salarial, dentre outros (FITIM, 2009c, p. 24-26; IVANOU, 2010a, s. p.; UAW et al., 2010, s. p.; OIT, 1951, s. p.).

Nas duas plantas analisadas neste trabalho, existiam contratos de protección ${ }^{(5)}$. Um deles era adotado pelo sindicato de papel ${ }^{(6)}$ na planta JC FINSA (Confederación Regional

(4) Os AMIs são acordados entre os dirigentes sindicais das FSIs e os diretores das matrizes de multinacionais (MNCs). Em tese, esses acordos atuam em cascata: as matrizes notificam as filiais de seu conteúdo, atingindo a base dos trabalhadores das empresas que celebraram os contratos.

(5) São firmados entre patronato e empresas privadas (geralmente, escritórios de advocacia) para aparentemente representarem trabalhadores. Na prática, são uma forma de fragilizar o movimento de trabalhadores mexicano.

(6) Sindicatos de papel ou fantasmas são, como o próprio nome sugere, instituições legais que exercem suas funções como representantes dos trabalhadores apenas no papel. Na prática, se estabelecem em dada empresa para receber contribuições sindicais sem gerar benfeitorias efetivas aos trabalhadores. 
Obrera Mexicana - CROM) e outro, pelo sindicato de papel na planta JC Interiores (Confederación de Organizaciones Sindicales - COS).

Essa conjunção de fatores - maquilas, contratos de protección, condições ruins de trabalho, baixos salários, inexistência de sindicalização de fato etc. — formaram a base para o descontentamento dos trabalhadores nas plantas da empresa.

\subsection{A FORMAÇÃO DA COALIZÃO}

A busca dos trabalhadores da planta FINSA da JC por um novo sindicato foi um evento de longa duração (mais de quatro anos), tendo se iniciado antes e terminado depois do desenrolar de outra história similar, ocorrida na planta Interiores.

A longa caminhada dos trabalhadores da FINSA se iniciou de forma "tradicional", ou seja, a partir da insatisfação com o "estado de coisas" no local de trabalho. Em outubro de 2006, um grupo de trabalhadores da FINSA passou a se reunir com integrantes do Centro de Apoyo al Trabajador (CAT, uma Organização Não Governamental) para discutir suas necessidades e a contínua incompetência do sindicato em atendê-las. Durante os meses seguintes, os operários estudaram as leis mexicanas de trabalho e os contratos coletivos de outras plantas, e formaram a Coalición Organizativa de Trabajadores y Trabajadoras de JC (COT-JC), que, no ato de sua fundação, contava com 30 membros. Na ocasião, os trabalhadores ainda não tinham acesso aos seus próprios contratos (FITIM, 2009a, p. 25-26; IVANOU, 2010a, s. p.; UAW et al., 2010, p. 1-5).

AJC e a CROM reuniram então os trabalhadores em uma assembleia para "alertá-los" a não esconder informações da empresa. Em junho de 2007, a CROM divulgou a formação de um comitê para tratar de negociação coletiva e revisão de pagamentos pela primeira vez, e, na mesma ocasião, passou a intimidar os trabalhadores, procurando-os em seus locais de trabalho. Alguns membros do comitê de revisão de pagamentos começaram a questionar os delegados dos sindicatos sobre as gratificações e o acordo coletivo. Como resultado, foram demitidos pela companhia, com base na Cláusula de Exclusão (id. ibid.). Esta cláusula concede à empresa o direito de demitir os trabalhadores não sindicalizados; entretanto, no caso dos sindicatos de papel, esta mesma cláusula permite que os trabalhadores que buscam a representação dos sindicatos autênticos sejam demitidos. O CROM justificou as demissões alegando que os trabalhadores procuravam um novo sindicato para se filiar. Entre os funcionários arbitrariamente demitidos, estavam Carmen Sánchez Juárez e Jorge Isidoro Aguilar Lara (id. ibid.). Abordaremos o caso de Carmen mais adiante.

Entre agosto e julho de 2008, a companhia identificou e demitiu mais 15 membros (aproximadamente) da coalizão. O processo para reintegração de oito desses trabalhadores, requerido na Junta Federal de Conciliación y Arbitraje (JFCA), seria concluído apenas em $1^{\circ}$ de julho de 2010. Em outubro de 2008, autoridades federais e estaduais do trabalho conduziram inspeções relacionadas a salários, saúde e segurança na planta. Os inspetores identificaram 18 violações, das quais quatro requeriam ações imediatas. Apesar das solicitações dos trabalhadores, nunca lhes foi entregue uma cópia do relatório de inspeção (id. ibid.). 
Em dezembro de 2008, a companhia despediu a maioria dos trabalhadores da One Digit, e passou a desligar outros, de diferentes áreas de produção, temporariamente, enquanto continuava a pagar aos seus empregados $50 \%$ de seus salários-base. Entre fevereiro e abril de 2009, cerca de 300 trabalhadores foram demitidos, incluindo membros da coalizão (id. ibid.). As ações da empresa eram, portanto, uma tentativa clara de desarticulação e intimidação dos trabalhadores.

\section{CONSTRUINDO O SINDICALISMO TRANSNACIONAL: O PROCESSO E SEUS RESULTADOS}

\subsection{A QUEIXA DA FITIM NA OIT}

Diversas organizações consideram que as condições trabalhistas no México (principalmente aquelas que envolvem os contratos de protección) são violadoras da liberdade sindical, ainda que a Convenção n. 87 tenha sido ratificada pelo país em 1950.

Por também considerar que a liberdade sindical é amplamente prejudicada em razão dos contratos de protección e a outros mecanismos praticados nas relações industriais do país, a FITIM apresentou sua queixa ao Comitê de Liberdade Sindical ${ }^{(7)}$ da OIT em fevereiro de 2009 (Complaint n. 2.694, of violations of the freedom of association and protection of the right to join a trade union $)^{(8)}$. Essa denúncia cita o caso dos trabalhadores da Johnson Controls ${ }^{(9)}$, e descreve as dificuldades de trabalhadores e sindicatos relacionadas à liberdade sindical e ao direito de filiação, como consequência de brechas na legislação mexicana, destacando os seguintes aspectos:

- facilidade dos empregadores em demitir seus trabalhadores, encerrar um contrato de protección e acordar outro ainda mais flexível (art. 401 da Ley Federal del Trabajo - LFT), e em perpetuar sindicatos fantasmas (art. 923 da LFT);

- inexistência de liberdade sindical e do direito de sindicalização;

- constatação de que a grande maioria dos contratos de proteção não beneficia os trabalhadores, por atenderem apenas ao mínimo requerido por lei;

- o fato dos contratos de protección serem legalizados por causa da cumplicidade das autoridades do trabalho e da JCA;

- existência de restrição tipológica dos sindicatos no art. 360 e restrição de seu campo de ação no art. 527 da LFT (por ramo de atividade e toma de nota ${ }^{(10)}$ ); e

(7) É uma ramificação do Conselho de Administração que tem como objetivo examinar queixas sobre a liberdade sindical, que podem ser feitas contra os Estados-membros (ORGANIZAÇÃO INTERNACIONAL DO TRABALHO, 2012b).

(8) FITIM, 2009a, Genebra. Complaint of violations of the freedom of association and protection of the right to join a trade union convention 87.

(9) A queixa cita o caso dos trabalhadores na Petróleos Mexicanos (PEMEX) e da Black \& Decker, além da Johnson Controls.

(10) Toma de nota é o registro dos sindicatos junto ao Poder Executivo e é um problema para os sindicatos que realmente desejam representar os trabalhadores no México, por duas razões fundamentais. A primeira diz respeito à participação do Estado nas relações capital-trabalho, descrita anteriormente. A segunda se refere à outra figura jurídica da legislação mexicana, o princípio de titularidad. De acordo com esse princípio, o sindicato que conseguiu seu registro (toma de nota) junto ao Executivo (em nosso caso, a Junta de Conciliación y Arbitraje - JCA) estará habilitado a representar 
- prática de espionagem, ataques, assaltos e ameaça de perda de emprego quando os trabalhadores buscam a representação de sindicatos autênticos (FITIM, Complaint 2.694, 2009, págs. 9-24).

Essa denúncia ilustra a corrupção no seio do Estado pelo relato dos problemas enfrentados pelos sindicatos para serem reconhecidos na JCA. De acordo com a Federação, ao tentar o reconhecimento na Junta, os sindicatos encontram dificuldades como necessidade de prova de vínculo empregatício e status local ou federal, incluindo evidências a que dificilmente os trabalhadores têm acesso. Ademais, frequentemente, as autoridades alegavam que a documentação apresentada não era clara ou era contraditória e os trabalhadores sofriam intimidação ao confirmar seu desejo de se filiar a um sindicato autêntico (id. ibid., p. 10-11).

A queixa também cita os fóruns nos quais o México participa, ressaltando que, por esse motivo, deve cumprir o princípio do pacta sunt servanda ${ }^{(11)}$ de acordos, tratados, convenções e organismos.

O governo mexicano respondeu a esses apontamentos indicando (sobretudo, mas não somente) que a legislação mexicana não prevê desvios que tornem injustas as relações entre capital e trabalho mostradas pela FITIM.

O Comitê de Liberdade Sindical concluiu que as declarações da FITIM e as respostas do governo mexicano são contraditórias, já que enquanto a primeira defende, por exemplo, que os contratos de protección são observados na prática, o segundo se concentra no plano legal. Também assinalou que, em ocasiões anteriores, solicitou reformas legislativas no México para reforçar direitos sindicais, tendo observado atrasos excessivos das autoridades administrativas ou judiciais em relação a registros sindicais e ao reconhecimento de certas juntas diretivas sindicais, além de ter tomado conhecimento do uso da violência entre facções sindicais buscando representação. Por fim, apontou que apesar das cláusulas de exclusión serem consideradas inconstitucionais pela Suprema Corte são observadas na prática (id. ibid., p. 257).

Diante desse quadro, a OIT convidou o governo mexicano a tomar medidas cabíveis e procurar fomentar um diálogo construtivo com as organizações de trabalhadores e empregadores sobre as cláusulas de exclusión, a representatividade mínima para a negociação coletiva e a alegada parcialidade e ineficiência das JCAs. Solicitou também que respondesse às declarações da FITIM relativas aos contratos de protección e aos casos de empresas apresentados ${ }^{(12)}$ (id. ibid., p. 257-258).

A FITIM continuou a observar de perto a situação dos trabalhadores da JC. A denúncia junto à OIT foi uma tentativa de despertar a atenção do Estado mexicano e da comunidade internacional. Ao Estado, a denúncia apontava mais uma vez as falhas legislativas e o gap entre a ratificação da convenção e a realidade; à comunidade internacional, chamava

os trabalhadores. Assim, uma vez que o sindicato possui a toma de nota (sendo esse sindicato de papel ou não, tendo boas intenções ou não), terá o direito de "representar" os trabalhadores de determinada localidade. Dito de outra forma, a lei claramente proíbe o pluralismo sindical (BAHENA, 2009, p. 72).

(11) Do latim: "os pactos devem ser respeitados", com base no princípio da boa-fé.

(12) Petróleos Mexicanos (PEMEX) e Johnson Controls. 
a atenção de investidores, empresas, organizações e outras partes interessadas para as possíveis condições domésticas no México. Além da denúncia apresentada em 2009, a FITIM divulgou, em 2010, pela sua revista bianual Metal World, o caso dos trabalhadores mexicanos.

É assim que a FITIM promove suas ações, por meio da publicidade, já que não tem a seu favor o poder de coação e coerção do Estado ou o mecanismo tripartite da OIT, e esse procedimento já é bastante conhecido entre os sindicalistas.

\subsection{CAMPANHAS E OS PRIMEIROS RESULTADOS: A PLANTA INTERIORES}

Os trabalhadores de ambas as plantas abordadas resolveram se filiar ao Sindicato Nacional de Trabajadores Mineros, Metalúrgicos y Similares de la República Mexicana (SNTMMSRM, também conhecido como "Los Mineros")no final de 2009, formando a comissão da sessão 308 do SNTMMSRM (com registro legal no México). Esse sindicato mantém parceria com o United Steelworkers (USW), sindicato estadunidense, e é filiado à FITIM. Segundo seu secretário, Sergio Beltrán, estavam sendo tomadas as medidas necessárias para receber a filiação dos trabalhadores das duas plantas da JC, dentre elas, a tentativa de um contato com a administração da empresa. O secretário relatou ainda que, para que isso ocorresse, seria importante que as Federações Sindicais Internacionais (incluindo a FITIM) atuassem como mediadoras e facilitadoras das reuniões com a companhia (apud SOLIS, 2010, s. p.).

A FITIM já promovia uma campanha global contra os contratos de protección antes da queixa contra o governo mexicano na OIT. The International Campaign Against Protection Contracts in México mantinha parcerias com grupos da sociedade civil, como a Universidad Autónoma de México (UNAM) e outras organizações internacionais. Os principais objetivos da campanha eram "identificar, denunciar e erradicar os contratos de proteção" (IVANOU, 2010b, s. p., tradução nossa).

Em 20 de maio de 2010, a FITIM engendrou outra campanha, denominada Call for action, após agressões sofridas por dois antigos trabalhadores da JC (abordaremos o caso com mais detalhes adiante). A campanha se baseava em três solicitações: o envio, pelos seus filiados, de uma carta ao governo mexicano, pedindo a segurança dos dois trabalhadores, de seus familiares e dos integrantes do CAT; a investigação dos sindicatos de papel; e o respeito aos direitos fundamentais do trabalho e à Convenção n. 87 (GARDNER, 2010a, s. p.). A FITIM também enviou uma cópia dessa carta às autoridades governamentais ${ }^{(13)}$ (MAQUILA SOLIDARITY NETWORK et al., 2010).

Em 25 de maio de 2010, 400 trabalhadores da planta Interiores assinaram cartões de filiação ao sindicato Los Mineros, acompanhados de integrantes do CAT e do Comitê

(13) Felipe de Jesus Calderon Hinojosa (Presidente Constitucional da República Mexicana em exercício), Fernando Gómez-Mont Urueta (Secretário-Geral do Governo), Arturo Chávez Chávez (Procurador-Geral da República), Javier Lozano Alarcón (Secretário do Trabalho e Previsão Social), Mario Marín Torres (Governador do Estado de Puebla), Héctor Ortiz Ortiz (Governador do Estado de Tlaxcala), Raúl Plascencia Villanueva (Presidente da Comissão Nacional de Direitos Humanos), Marcia Maritza Bullen Navarro (Presidente da Comissão de Direitos Humanos do Estado de Puebla), Jesús Ortiz Xilotl (Presidente da Comissão de Direitos Humanos do Estado de Tlaxcala). 
Executivo Nacional do novo sindicato, manifestando assim seu desejo de anular o contrato de protección com o sindicato de papel vigente, a COS. Também solicitaram à empresa o pagamento da participação nos lucros prevista, e as demandas foram apresentadas à diretora de recursos humanos da planta, Maricela Rodriguez. A companhia se negou a eliminar a COS, argumentando que essa iniciativa cabia aos trabalhadores, e não à empresa. No dia 26 do mesmo mês, um veículo com 70 membros da COS adentrou o pátio da JC, se aproveitando de um simulacro de incêndio realizado para retirar os funcionários de dentro da companhia; porém, os trabalhadores não se deixaram enganar. Após o incidente, o CAT passou a manter vigilância sobre o pátio [ESPINOSA (2010?), p. 1-4; GARDNER, 2010b, s. p.].

Segundo o United States Labor Education in the Americas Project (USLEAP), nesse mesmo dia, representantes da Secretaría Federal del Trabajo foram até a JC Interiores, e a empresa permitiu também que os 70 integrantes da COS entrassem em suas dependências. A greve iniciou-se no mesmo dia e, por três dias consecutivos, 342 trabalhadores cruzaram os braços. A capacidade da planta de atender a grandes clientes caiu vertiginosamente. Finalmente, os trabalhadores conquistaram o direito de serem representados pelo sindicato Los Mineros, no final do mesmo mês. Ao que tudo indica, "a pressão de ações solidárias locais e internacionais fizeram com que o representante da JC, o subsecretário do trabalho no estado de Puebla e o presidente da Delegación Federal del Trabajo de Puebla chegassem e pedissem para negociar com os trabalhadores" (apud GARDNER, 2010c, s. p., tradução nossa). Nessa ocasião, foram feitosos seguintes acordos:

- a Johnson Controls finalizará sua relação legal com a COS;

- a Johnson Controls reconhecerá a liberdade sindical, manifestada pelo desejo de se filiar a Los Mineros (SNTMMSSRM) e, em consequência, a Johnson Controls providenciará todo o suporte necessário para o registro do acordo coletivo;

- a companhia não tomará nenhuma medida legal contra os trabalhadores com base na paralisação;

- não haverá represálias contra os trabalhadores que participaram do movimento;

- a companhia pagará $100 \%$ do tempo perdido na paralisação;

— os trabalhadores receberão $\$ 100$ de bônus em 31 de maio;

— os trabalhadores retornarão ao trabalho no dia 31 de maio;

— os representantes dos trabalhadores não enviarão comunicados à companhia no México ou à matriz nos Estados Unidos sobre situações trabalhistas que não são verdadeiras;

- a companhia oferecerá emprego aos trabalhadores subcontratados da One Digit. (GARDNER, 2010d, s. p., tradução nossa).

Diversos sindicatos adotaram resoluções no sentido de oferecer suporte aos trabalhadores da planta JC FINSA, exigindo que a companhia respeitasse seus direitos, a exemplo do que já acontecera na planta Interiores, cuja conquista foi resultado de uma reunião que incluiu trabalhadores e sindicatos da Alemanha, Bélgica, Eslováquia, Espanha, França, Polônia e República Checa, e instituições como European Metalworkers' Federation (EMF), 
European Mine, Chemical and Energy Workers' Federation (EMCEF), European Trade Union Federation - Textiles, Clothing and Leather (ETUF-TCL) e a UNIGlobal Union. Essas entidades manifestaram sua satisfação em relação aos resultados obtidos pelos trabalhadores da planta Interiores, relembraram os direitos garantidos pelas Convenções ns. 87 e 98 da OIT e destacaram o monitoramento que a mesma exerceu sobre a questão (EUROPEAN METALWORKERS' FEDERATION et al., 2010, s. p.).

A situação parecia estar resolvida na JC Interiores. Com efeito, a carta conjunta dos sindicatos europeus parecia indicar que o caso dos trabalhadores da JC em Puebla caminhava para um final feliz.

Entretanto, se constatou que o acordo era apenas parcialmente cumprido. Novos ataques aconteceram na planta Interiores em 16 de agosto daquele ano de 2010: pessoas estranhas tiveram acesso à planta, e os trabalhadores foram destratados e atingidos por paus e pedras. Dois membros do Comitê Executivo de Los Mineros (Cándido Barreucos e Vigilio Melendez) foram agredidos dentro de um escritório da companhia, e forçados a assinar cartas de demissão sob a ameaça de armas de fogo, tendo que ser hospitalizados após o incidente. Los Mineros acredita que as pessoas responsáveis pelos atentados eram integrantes da COS (GARDNER, 2010e, s. p.; CORDERO, 2010, s. p.).

Por causa desse incidente, a FITIM pediu que seus filiados enviassem cartas à JC e ao governo mexicano, exigindo o fim da violência na planta. A carta à empresa podia ser enviada diretamente, pelo site ${ }^{(14)}$, e se encontrava disponível para download, devendo ser encaminhada a Mr. Stephen A. Roell, presidente e Chief Executive Officer (CEO) da Johnson Controls, com cópia para Jerry Okarma, vice-presidente e conselheiro geral. O site disponibilizava o endereço eletrônico profissional de ambos, assim como das autoridades governamentais e pessoas ligadas aos direitos humanos ${ }^{(15)}$ (GARDNER, 2010e, s. p.).

Em acordo datado de 18 de agosto de 2010, os trabalhadores da JC Interiores finalmente conseguiram o reconhecimento de Los Mineros como seu sindicato legítimo e definitivo, mas não sem antes passarem por uma nova mobilização local (uma greve de quatro dias). O contrato com a COS foi rescindido, e outro foi "registrado na JCA local, sob a seção 765 da página 383 do livro de registros da Junta, datado de seis de julho de 2005, onde um contrato coletivo de trabalho por acordo privado foi encerrado por consenso das partes sob os termos da Seção I do Art. 401 da Ley Federal del Trabajo [...] devidamente depositado na Junta Local de Conciliación y Arbitraje de Puebla, Puebla". (JOHNSON CONTROLS SERVICES; SINDICATO NACIONAL DE TRABAJADORES MINEROS, METALÚRGICOS, SIDERÚRGICOS, Y SIMILARES DE LA REPÚBLICA MEXICANA, 2010, p. 3, tradução nossa).

Em outro acordo, a companhia se comprometeu a readmitir os trabalhadores obrigados a renunciar, indenizar seis trabalhadores feridos e examinar dois supervisores que fizeram

(14) Disponível em: <http://www.imfmetal.org/index.cfm?n=753\&l=2> Acesso em: 23 out. 2011, às 22h52m.

(15) Eram destinatários da carta: Felipe de Jesús Calderón Hinojosa, presidente mexicano em exercício, com cópia para Javier Lozano Alarcón (Secretário do Trabalho e Previsão Social), Mario Marín Torres (Governador do Estado de Puebla) e Raúl Plascencia Villanueva (Presidente da Comissão Nacional de Direitos Humanos). Disponível em: <http:// www.imfmetal.org/index.cfm?n=751\&l=2> Acesso em: 23 out. 2011, às 22h54m. 
"vista grossa" aos maus-tratos infligidos aos líderes. O acordo foi realizado entre a empresa, Los Mineros e a comissão dos trabalhadores ${ }^{(16)}$.

Entretanto, para infelicidade dos trabalhadores da JC Interiores, o novo acordo, mais uma vez, foi apenas parcialmente cumprido. Além disso, existiam rumores de fechamento dessa planta.

Em nove de abril de 2011, Los Mineros fizeram sua primeira negociação com a empresa, quando houve uma tentativa fracassada de "recontagem" de trabalhadores interessados em tê-los como seus representantes. Já o governo do estado negou o reconhecimento do contrato firmado com a COS, ponto decisivo para o reconhecimento do novo sindicato. Dentre as benesses concedidas aos trabalhadores, destacamos: aumento salarial de 7,5\% (contra $1 \%$ ou $2 \%$ geralmente negociados entre a COS e a empresa); acréscimo na ajuda escolar, que passou de 600 para 650 pesos por filho; o seguro de vida por morte natural, que era de 12.000 pesos, passou para 35.000 pesos; e o seguro de vida por acidente de trabalho subiu de 12.000 para 45.000 pesos (JIMÉNEZ, T., 2010, s. p, IVANOU, 2011, s. p.).

\subsection{DO USO DA VIOLÊNCIA (A REAÇÃO DOS SINDICATOS DE PAPEL)}

Como foi dito anteriormente, antes das conquistas obtidas pelos trabalhadores da planta Interiores, em agosto de 2010, os trabalhadores da planta JC FINSA já haviam formado a coalizão para defesa de seus direitos. Nesse caso, o sindicato de papel que obtivera os requisitos legais de representação era a CROM, que inclusive era detentora do contrato de protección na fábrica.

Carmen Sanchez Juarez figurava entre as cinco pessoas eleitas pelos trabalhadores da FINSA para formar a comissão que os representaria. Esses cinco representantes, porém, foram demitidos, a despeito da fábrica estar trabalhando com $90 \%$ de sua capacidade produtiva, aparentemente por causa de suas demandas de revisão das provisões de pagamento e do acordo coletivo (IVANOU, 2010c, s. p.).

A campanha de 2009-2011, de que trataremos a seguir, foi antecedida por outra, em junho de 2007 que, no entanto, foi rapidamente suprimida. Naquela ocasião, alguns trabalhadores estavam participando da Comisión Revisora del Reparto de Utilidades, que exigia um novo contrato coletivo de trabalho, além da PLR (id. ibid., 2010). Como mencionamos acima, os funcionários da FINSA desejavam ser representados por Los Mineros, a exemplo dos trabalhadores de outra planta da mesma empresa, a Interiores.

Carmen Sanchez, agora apenas integrante da coalizão do CAT juntamente com outras três desempregadas pela JC (Ofelia Morales Cote, Anabel Flores e Angélica Monte Alegre), em uma visita a suas antigas colegas de trabalho, foi seguida por MagdalenoTexis e Marcelino Tecuapacho, integrantes da CROM, em 6 de janeiro de 2009. Em novembro do mesmo ano, esses mesmos membros da CROM fizeram ameaças aos trabalhadores da JC, dizendo que "se eles se filiassem ou abrissem as portas de sua casa aos integrantes do CAT arcariam com as consequências" (PRODESC et al., 2010, p. 4, tradução livre). Carmen seria

(16) Executive Commitee of Local 308 at the Johnson Controls Services company located on the Mexico Puebla Highway n. 296 of the Industrial Park of the Resurrection, Puebla. 
novamente ameaçada por Tecuapacho em 11 de abril de 2010, na vila em que morava, San Luis Teolocholco, quando se dirigia ao novo sindicato (Los Mineros) (ibid., p. 4-5). Os três episódios envolvendo ameaças contra pessoas ligadas à JC eram apenas um indicativo da disposição de usar a força por parte de Tecuapacho e Texis, da CROM. Demonstrações ainda mais enfáticas estavam por vir, em outras instituições e esferas.

Enrique Morales Montaño era, na ocasião, membro do CAT, e trabalhava junto à coalizão da JC, ao lado de Coral Juarez Melo, uma representante dos trabalhadores da JC no CAT. Em 28 de abril de 2010, Enrique e Coral dirigiam-se a Santo Toribio, em Tlaxcala, para visitar os trabalhadores, quando foram atacados e ameaçados pelo filho de 17 anos de Magdaleno Texis, que falou: "deixe de ser estúpido senão eu te mato, e deixe de fazer tanta chingadera contra o meu pai [...]é um recadinho de Magdaleno Texis y Marcelino Tecuapacho, que este era um aviso e que depois iriam acabar com os demais filhos da chingada do CAT" (apud PRODESCS et al., 2010, p. 2, tradução nossa). Coral, tendo notado que um grupo de pessoas se aproximava, começou a gritar, pedindo ajuda a um auxiliar de polícia (ibid.).

De acordo com Enrique e Coral, o conselho dado por esse funcionário foi: "melhor que cheguem a um acordo e que lhes paguem os danos, porque na procuradoria seria mais difícil" (apud PRODESC et al., 2010, p. 2, tradução nossa). Conforme nos explicou Inés Gonzaléz, da FES do México, muitos dos sindicatos fantasmas que possuem contrato de protección em um local assinam contrato legítimo em outro (informação verbal) ${ }^{(17)}$, tornando sua existência reconhecida pelos trabalhadores.

Os membros do CAT resolveram fazer sua reclamação na polícia, ao invés de negociar diretamente com o sindicato de papel, e somente após passarem por alguns escritórios do estado (Santo Toribio e San Pablo del Monte), Enrique e Coral conseguiram registrar a ocorrência na Procuradoria do estado de Tlaxcala, após revisão médica, à lh30min da madrugada (id. ibid.). Em 30 de abril, o filho de Texis foi preso, mas liberado sob fiança, por ser menor de idade. Após o ocorrido, o CAT buscou registrar um reclame na Comissão de Direitos Humanos do Estado, incluindo um pedido de medidas de precaução (USLEAP, 2010, s. p.).

Ainda que Texis tenha declarado ao Ministério Público que ele ou seu filho não mais atacariam membros do CAT (PRODESC; CAT, 2010, p .1), em 9 de agosto, Enrique e Coral seriam ameaçados novamente, assim como outro membro do CAT, Maria Luisa Rosina, em San Luis Teolocholco, durante um trabalho de campo (treinos de direitos trabalhistas e repasse de informações). Na ocasião, um homem não identificado os abordou, dizendo que "sabia que eles eram do CAT e deveriam dizer à Blanca ${ }^{(18)}$ que se ela continuasse se intrometendo nos assuntos da CROM haveria consequências" (GARDNER, 2010e, s. p., tradução nossa).

Apesar das ameaças, demissões, listas negras e violência física, a coalizão COT-JC conseguiu formalizar o pedido de representação de Los Mineros na JCA. Nesse ínterim, houve tempo para um roubo ao escritório do CAT, em 20 de dezembro de 2010.

(17) Informação fornecida por Inés Gonzaléz, pesquisadora da FES no México, em entrevista realizada em 1ํ de junho de 2012.

(18) Diretora Executiva do CAT. 
Em 11 de janeiro de 2011, Blanca Velázquez tentou se conectar à sua conta de e-mail pessoal e institucional a fim de enviar informações aos integrantes do CAT, sem sucesso. Três dias depois, dois e-mails foram enviados a todos os membros do Centro, com detalhes do atentado sofrido por Digna Ochoa, advogada mexicana de direitos humanos, em outubro de 1999 (ibid., 2010), que faleceu em 19 de outubro de 2001.

\subsection{A CAMPANHA INTERNACIONAL: GLOBAL DAYS OF ACTION}

As ameaças aos integrantes do CAT, se utilizando inclusive do exemplo do ataque efetivo a Digna Ochoa, e a crescente desesperança envolvendo os trabalhadores da JC marcaram a realização do $32^{\circ}$ Congresso da FITIM.

A partir da votação da Resolução n. 8 desse congresso (Solidariedade com a autonomia dos sindicatos e com a luta de Los Mineros, tradução livre), proposta pela Federación Nacional de las Actividades Mineras, Energéticas, Petroleras, Siderúrgicas y Complementarias del Perú (FENAMEPSICOP), a FITIM e seus filiados decidiram continuar repudiando os ataques realizados contra Los Mineros, além de: apoiar tanto o sindicato quanto seu líder, Napoleón Gómez Urrutia; relembrar as más condições de trabalho que levaram ao acidente em Pasta de Conchos ${ }^{(19)}$; solicitar do governo mexicano ações no sentido de evitar conflitos e soluções que não empregassem a violência (FITIM, 2009b, p. 1) ${ }^{(20)}$.

A campanha derivada dessa decisão, Global Daysof Action, colocou em ação os diversos atores e organizações ligados à JC relacionados aos direitos humanos e à busca pela liberdade sindical.

Pela FITIM, a campanha foi articulada junto aos seus próprios filiados, filiados de outras FSIs e sindicatos nacionais. A proposta era encorajar esses atores e interessados no tema a pressionar o governo mexicano para que este tomasse medidas relativas à liberdade sindical, que, segundo as evidências examinadas, parece ter sido suprimida pelo próprio país.

A campanha abrangia um período definido — de 14 a 19 de fevereiro de 2011 sendo que o último dia era uma alusão e uma homenagem aos 65 trabalhadores mortos na mina de carvão Pasta de Conchos. O que tornou ainda mais dramática e apelativa a situação foi o fato de que 63 dos 65 corpos permaneciam soterrados, e as investigações independentes, como as solicitadas por Los Mineros, não foram autorizadas. Comparativamente, quando 33 mineiros chilenos ficaram sob a terra após um acidente na mina de São José em agosto de 2010, o governo realizou um esforço descomunal, amplamente televisionado, por quase 70 dias, para resgatá-los, e esse fato foi relembrado na campanha empreitada pela FITIM (ITWF et al., 2010, p. 3).

A campanha cita os problemas da toma de nota e dos contratos de protección, a falha do Estado mexicano em atender às demandas de seus trabalhadores, a negação da toma

(19) Acidente ocorrido em uma mina no estado de Coahuila, México, em 19 de fevereiro de 2006, quando 65 mineiros morreram soterrados e apenas dois corpos foram resgatados.

(20) FTIM, 2009b, Gotemburgo. Item 12. Resolution n. 8. Solidarity with trade union autonomy and the struggle of the Mexican National Miners Union. Proposalby FENAMEPSICOP, PERU. 32ํㅡㄴ IMF World Congress. Gotemburgo: Federação... 24-28 maio 2009. 
de nota ao secretário-geral de Los Mineros no Comitê Central do SME, a dificuldade dos trabalhadores da Telefônica/Atento e da PEMEX em escapar do contrato de protección, a morte de cinco sindicalistas em campo e o caso CAT/JC. Deste, especificamente:

Acredita-se que as ameaças por escrito e os ataques contra o CAT estão ligados a um sindicato de protección, dado o fracasso da JC em cumprir o acordo de 10 de agosto com o sindicato independente.

Tal retaliação e violência contra os trabalhadores que se associam a sindicatos independentes não seria possível se não houvesse tolerância e cumplicidade do governo.

O fracasso do governo em fazer cumprir os direitos dos trabalhadores e em investigar e punir os perpetradores de tal intimidação violência é inaceitável [...].

Todos os tribunais estaduais e federais que analisaram as ações contra o secretário-geral da SNTMMSRM concluíram que tais ações são infundadas. Entretanto, o seu governo continua a perseguir o SNTMMSRM e o SME, através de métodos que variam da negação da toma de nota, congelamento das contas bancárias dos sindicatos, ao aprisionamento baseado em falsas acusações de Juan Linares, líder do SNTMMSRM, desde 2008, e Miguel Marquez Rios, líder do SME, desde 2010. Os líderes aprisionados injustamente devem ser liberados, e os danos sofridos, remediados (FITIM, 2011, tradução nossa).

Assim, a carta pedia ação imediata para:

1. A prisão do empregador e dos oficiais governamentais responsáveis pela explosão e investigação da mina Pasta de Conchos, que matou 65 mineiros em 19 de fevereiro de 2006.

2. Abolir as violações sistemáticas da liberdade sindical dos trabalhadores, incluindo os "contratos de proteção" dominados pelo patronato e a interferência nas eleições dos sindicatos.

3. Cessar o uso da força - pelo Estado ou por entes privados - para reprimir as demandas legítimas dos trabalhadores por sindicatos democráticos, melhores salários e condições de trabalho, e boas condições de saúde e segurança do trabalho.

4. Finalizar a campanha de perseguição contra Los Mineros e contra o SME (ITWF et al, 2010, p. 4-7, tradução livre).

Ainda que essas mobilizações fossem direcionadas aos filiados das FSIs, qualquer pessoa com acesso à internet poderia se juntar ao movimento e denunciar a situação mexicana, já que tanto o modelo de carta a ser enviado às autoridades mexicanas, quanto os folders e outros materiais necessários para distribuição estavam disponíveis, formatados e claros no site da Federação. Por exemplo, a carta a ser enviada diretamente ao presidente Calderón ${ }^{(21)}$ era disponibilizada em inglês, castelhano, norueguês, italiano, português, holandês, turco e árabe, assim como o material de campanha (pôsteres, flyers, informações adicionais e cartas às autoridades) ${ }^{(22)}$.

(21) Disponível em: <http://www.imfmetal.org/index.cfm?c=24820\&l=2> Acesso em: 21 out. 2011, 16h02m.

(22) Disponível em: <http://www.imfmetal.org/index.cfm?c=24820\&l=2> Acesso em: 21 out. 2011 às 16h02m. 
As ações dos sindicatos nacionais, em consonância com os pedidos das FSIs, consistiram em comícios, reuniões com embaixadores mexicanos, cartas e e-mails em massa, atingindo 30 países $^{(23)}$ ao redor do mundo.

Houve também uma campanha nacional no México. Essa campanha, em articulação com as FSIs, foi realizada por sindicatos para reiterar, publicamente, a necessidade de mudança das condições de trabalho mexicanas.

O grupo de direitos humanos Proyecto de Derechos Económicos, Sociales y Culturales e o CAT enviaram cartas a diversas autoridades nacionais e internacionais ${ }^{(24)}$, solicitando investigação e medidas de segurança sobre o caso (PRODESC; CAT, 2010, p. 2; 2011, p. 2). Outra carta foi encaminhada ao vice-presidente da JC nos Estados Unidos, Jerry Okarma, escrita em conjunto pela FITIM, Canadian Auto Workers, United Steelworkers, United Auto Workers e Los Mineros, solicitando:

[...] que seja requerido tanto ao atual governador de Puebla quanto ao governador a tomar posse que as atuais autoridades diligentemente investiguem e se tomem medidas legais em relação às ameaças e atos de intimidação direcionados aos ativistas do CAT, e que seus representantes locais se encontrem pessoalmente com os poderes oficiais para reforçar essa mensagem. Também solicitamos que essas cartas sejam distribuídas aos seus funcionários e à mídia.

Também pedimos que dissociem publicamente a Johnson Controls dessas ações e informem aos seus trabalhadores, sindicatos e autoridades locais que a companhia respeita o direito sindical dos trabalhadores tanto nos locais de trabalho quanto em suas comunidades. (UNITED STEELWORKERS et al., 2011, tradução nossa.)

Após essas movimentações amplas de âmbito mundial com solidariedade entre instituições de diversos países, houve mudança para os trabalhadores das plantas FINSA e Interiores.

\subsection{FECHAMENTO DA PLANTA INTERIORES}

De acordo com Suzanna Miller (responsável por projetos para o México na FITIM), todas as unidades produtivas da JC no México eram ligadas a sindicatos de papel e, dentre todas as plantas estudadas, apenas os trabalhadores da Interiores conseguiram a representação de um sindicato livre das características dos sindicatos de papel (informação verbal) ${ }^{(25)}$.

(23) África do Sul, Alemanha, Argentina, Armênia, Austrália, Bangladesh, Belarus, Bélgica, Brasil, Bulgária, Canadá, Colômbia, Coreia, El Salvador, Espanha, Estados Unidos, Finlândia, França, Grã-Bretanha, Holanda, Hong Kong, Índia, Indonésia, Itália, Japão, Quirguistão, Moçambique, Nova Zelândia, Noruega, Peru, Polônia, Porto Rico, Rússia, Sri Lanka, Suécia, Suiça, Tailândia, Turquia, Ucrânia.

(24) Felipe de Jesús Calderón Hinojosa (Presidente Constitucional da República), José Francisco Blake Mora (Secretário-Geral do Governo), Arturo Chávez Chávez (Procurador-Geral da República), Mario Marin (Governador do Estado de Puebla), Rodolfo Igor Archundia Sierra (Procurador-Geral de Justiça do Governo do Estado de Puebla), Marcia Maritza Bullen Navarro (Presidente da Comissão de Direitos Humanos do Estado de Puebla), Escritório da Alta Comissão das Nações Unidas para os Direitos Humanos no México, Comissão Interamericana de Direitos Humanos, Santiago Cantón (Secretário-Executivo da Comissão Interamericana de Direitos Humanos), Navanethem Pillay (Alta Comissionada das Nações Unidas para os Direitos Humanos).

(25) Entrevista concedida em 24 de maio de 2012. 
Contudo, a vitória de Los Mineros na planta Interiores parecia ser o primeiro passo rumo à eliminação dos sindicatos de papel nas bases dos trabalhadores da empresa em questão.

Entretanto, o futuro reservava uma realidade ainda mais amarga aos trabalhadores, à FITIM, a Los Mineros e a todas as outras instituições e pessoas envolvidas no caso. Como em uma autêntica novela mexicana, os trabalhadores da Interiores foram demitidos, sob a alegação de que a planta era financeiramente inviável, a despeito da empresa ter apresentado lucros 15\% maiores em comparação ao ano anterior. No processo, a Seção 308, formada por Los Mineros para representação, foi eliminada, e 380 dos 440 trabalhadores, demitidos. (LOS MINEROS, 2012, s. p.; SOLIS, 2012a, s. p.). A empresa também argumentou que a localização da planta era um entrave logístico, e que os volumes de produção estavam se tornando baixos (RANGEL, 2012, s. p.; MARTíNEZ, 2012a, s. p.). A planta migrou para Querétaro (MARTÍNEZ, 2012a, s. p.; JIMÉNEZ, A., 2012, s. p.), um estado mexicano conhecido pela sua política altamente antissindical ${ }^{(26)}$. O sindicato Los Mineros e o CAT (2012, s. p.) estão convencidos de que essa decisão foi um golpe contra o sindicalismo independente conquistado pelos trabalhadores da planta.

O fechamento da planta ocorreu em meio à campanha Global Days of Action, que completara seis anos em 2012 (SOLIS, 2012b, s. p.). Após o sequestro de Enrique Morales Montaño e a ameaça de morte à Blanca Velásquez (SOLIS, 2012c, s. p.), o CAT encerrou definitivamente suas atividades (MARTíNEZ, 2012b, s. p.).

\section{CONSIDERAÇÕES FINAIS}

O presente artigo buscou analisar a internacionalização da campanha em favor dos trabalhadores da maquila estadunidense Johnson Controls. Para tanto, traçamos um histórico das condições dos trabalhadores em duas plantas específicas desta empresa (FINSA e Interiores), dos passos tomados pela FITIM na promoção da campanha em questão e das formas de pressão sobre os problemas macroestruturais das relações laborais mexicanas, como: a reclamação junto à OIT, as informações sobre a situação do México em seu site, a promoção de campanhas por e-mails, a campanha ampla da Global Days of Action e o relacionamento da Federação com os sindicatos nacionais e com outras organizações internacionais que atuam junto aos trabalhadores.

Conforme pudemos verificar, os ganhos obtidos pelos trabalhadores da planta Interiores na empresa Johnson Controls foram de curto prazo, tendo em vista o fechamento da planta, sua migração para Querétaro e a demissão de 380 dos 440 trabalhadores desta unidade produtiva. Comprova-se, neste estudo de caso, uma questão que é quase consensual na Academia: a mobilidade relativa do capital é muito maior que a relativa localidade e estagnação do trabalho, sendo que o primeiro vetor tem vantagem sobre o segundo. O "exército industrial de reserva" nos países do centro, e principalmente nos países da periferia, contribui para a perpetuação desse cenário.

Portanto, como pudemos verificar, ganhos individuais e pontuais - como ilustra o caso dos trabalhadores da planta Interiores da JC — são mais facilmente sufocados pelo

(26) Informação fornecida por Suzanna Miller em entrevista concedida em 24 de maio de 2012. 
patronato. Uma alternativa seria a construção de redes em uma dada empresa, o que possibilitaria aos trabalhadores formar contatos permanentes e duradouros, como acontece nas empresas Gerdau e Mercedes-Benz.

Percebe-se que o Estado ainda possui papel central nas relações entre capital e trabalho, independentemente das estruturas legais que regulam tais relações, ou do país em questão.

A organização sindical, a despeito dos esforços internacionais, ainda é preponderantemente nacional [EDER, 2002, p. 178; EVANS, 2010, p. 365; HOBSBAWM, 2000 (1984), passim] e não existem evidências de que esse quadro possa mudar substancialmente. A organização no local de trabalho não é apenas mais importante que a organização de sindicatos de forma internacional ou transnacional: é imprescindível. Contudo, podemos afirmar que as organizações transnacionais são importantes. Uma dessas instituições, a FITIM, foi objeto de estudo neste trabalho, sendo que (não menos importante) a OIT também foi abordada. Tais instituições refletem o desejo de pessoas unidas por objetivos comuns que ultrapassam suas fronteiras nacionais (TARROW, 2001, p. 15), mesmo sendo alvo de múltiplas críticas contundentes, como aquelas proferidas por Cox (2009, p. 12).

Quanto aos sindicatos, suas estratégias de constrangimento às empresas também funcionam perante os Estados, como vimos acontecer no caso da denúncia da FITIM à OIT, fazendo com que o México prestasse algum accountability à comunidade internacional.

\section{REFERÊNCIAS BIBLIOGRÁFICAS}

CASTELLS, Manuel. A sociedade em rede. vol. I. 6. ed. São Paulo: Paz e Terra, 1999.

CORDERO, Miguel Ángel. Gresca sindical estalla en Johnson Controls. La Quinta columna. Puebla, 17 ago. 2010. Disponivel em: <http://www.quintacolumna.com.mx/notas/2010/agosto/politica/ pol-170810-mig-gresca-sindical-estalla-en-johnson-controls.php> Acesso em: 22 maio 2012, 16:39.

COX, Robert W. The global political economy and social choice. In: COX, Robert. SINCLAIR, Timothy J. Approaches to world order. Cambridge: Cambridge University Press, 1996 [1991].

ESPINOSA, Socorro. JCI, un conflito sin resolver. Status Puebla. Puebla, [2010?]. Disponível em: $<$ http://www.statuspuebla.com.mx/index.php?option=com_content\&view=article\&id=4888\&Ite mid=73> Acesso em: 24 maio 2012.

EUROPEAN METALWORKERS' FEDERATION et al. Resolution of the trade union coordination group on Johnson Controls. Bruxelas, Bélgica, 7 jun. 2010. Disponível em: <http://www.emf-fem.org/ Press/Solidarity-archive/Resolution-of-the-trade-union-coordination-group-on-JohnsonControls> Acesso em: 17 maio 2012.

FEDERAÇÃO INTERNACIONAL DE TRABALHADORES DAS INDÚSTRIAS METALÚRGICAS, 2009a, Genebra. Complaint of violations of the freedom of association and protection of the right to join a trade union convention 87.Genebra: Federação... reclamação endereçada ao comitê de liberdade sindical da Organização Internacional do Trabalho. Disponível em: <http://www.imfmetal. org/files/12021711024279/IMF_complaint_to_ILO_2009_EN.pdf> Acesso em: 18 maio 2012.

2009b, Gotemburgo. Item 12. Resolution n. 8. Solidarity with trade union autonomy and the struggle of the Mexican National Miners Union. Proposal by FENAMEPSICOP, PERU. $32^{\circ}$ IMF World Congress. Gotemburgo: Federação... 24-28 maio 2009. 
Model letter to Mexican embassies (english version). 2011. Disponível em: <http:// www.imfmetal.org/index.cfm?c=24820\&l=2> Acesso em: 18 maio 2012, 20:29.

GARDNER, Anita. Call for action against assault on JC organizers in Mexico. Federação Internacional de Trabalhadores da Indústria Metalúrgica. Genebra, 19 maio 2010(a). Disponível em: <http:// www.imfmetal.org/index.cfm?c=23049\&l=2> Acesso em: 08 out. 2011.

More Johnson Controls workers under attack in Mexico. Federação Internacional de Trabalhadores da Indústria Metalúrgica. Genebra, 27 maio 2010(b). Disponível em: <http://www. imfmetal.org/index.cfm?c=23170> Acesso em: 29 out. 2011.

Trabajadores de Johnson Controls conquistan la representación sindical democrática. Federação Internacional de Trabalhadores da Indústria Metalúrgica. Genebra, 31 maio 2010(c). Disponível em: <http://www.imfmetal.org/index.cfm?c=23193\&ol=28> Acesso em: 14 out. 2011.

Johnson Controls workers win democratic union representation. Federação Internacional de Trabalhadores da Indústria Metalúrgica. Genebra, 31 maio 2010(d). Disponível em: <http://www.imfmetal.org/index.cfm?c=23193> Acesso em: 19 out. 2011.

Renewed attacks on Johnson Control workers. Federação Internacional de Trabalhadores da Indústria Metalúrgica. Genebra, 18 ago. 2010(e). Disponível em: <http://www.imfmetal. org/index.cfm?c=23788\&l=2> Acesso em: 19 out. 2011.

GORENDER, Jacob. Globalização, tecnologia e relações de trabalho. Estudos avançados. São Paulo, v. 11, n. 29, jan./abr. 1997.

HARVEY, David. Condição pós-moderna. 16.ed. São Paulo: Edições Loyola, 1992.

HOBSBAWM, Eric J. Mundos do trabalho: novos estudos sobre história operária. 4. ed. Rio de Janeiro: Paz e Terra, 2000 [1984].

INTERNATIONAL TRANSPORT WORKERS' FEDERATION et al. Mexico Days of Action: 14-19 February 2011. Genebra, 01 dez. 2010. Disponível em: <http://www.imfmetal.org/files/11012116125310005/Fact\%20sheet_en.pdf> Acesso em: 20 maio 2012.

IVANOU, Alex. Mexico: The fight for a representative union. Federação Internacional de Trabalhadores da Indústria Metalúrgica. Genebra, 19 maio 2010(a). Disponível em: <http://www.imfmetal. org/index.cfm?c=23045> Acesso em: 08 out. 2011.

The international fight against protection contracts. Federação Internacional de Trabalhadores da Indústria Metalúrgica. Genebra, 19 maio 2010(b). Disponível em: <http://www. imfmetal.org/index.cfm?c=23048> Acesso em: 20 out. 2011.

Mineros sign first contract at Johnson Controls in Puebla. Federação Internacional de Trabalhadores da Indústria Metalúrgica. Genebra, 14 abr. 2011. Disponível em: <http://www. imfmetal.org/index.cfm?c=26266\&l=2> Acesso em: 23 out. 2011.

JIMÉNEZ, Aarón Martínez. Gobierno es corresponsable por cierre de Johnson Controls: COE. NG Puebla. Puebla, 20 mar. 2012. Disponível em: <http://www.ngpuebla.com/negocios/16010gobierno-es-corresponsable-por-cierre-de-johnson-controls-coe> Acesso em: 27 maio 2012.

JIMÉNEZ, Tania Damián. En puerta, la solución en Johnson Controls; la empresa aceptaría a un nuevo sindicato. La Jornada de Oriente. Puebla, 18 ago. 2010. Disponível em: <http://www.lajornadadeoriente.com.mx/2010/08/18/puebla/ecol03.php> Acesso em: 25 maio 2012.

JOHNSON CONTROLS. Produtos e Soluções. Disponível em: <http://www.johnsoncontrols.com. br/publish/br/pt/products/power_solutions/marcas.html> Acesso em: 08 set. 2011.

Locations. Disponível em: <http://www.johnsoncontrols.com/publish/us/en/locations.html> Acesso em: 22 maio 2012. 
JOHNSON CONTROLS SERVICES et al. $1^{\underline{o}}$ Acordo entre Johnson Controls, los Mineros e Comissão de Trabalhadores da JC Interiores. Puebla 20 ago. 2010. Disponível em: <http://en.maquilasolidarity. org/sites/maquilasolidarity.org/files/2010-08-19-JCI-Agreement-ENG.pdf?SESS89c5db4la82abcd 7da7c9ac60e04ca5f=mrdvpcufw > Acesso em: 20 maio 2012.

JOHNSON CONTROLS SERVICES et al. $2^{\circ}$ Acordo entre Johnson Controls e Los Mineros. Puebla, 18 ago. 2010. Disponível em: <http://www.imfmetal.org/files/10083014194810005/2010-08-20\%20 Acuerdo\%20JCI\%20II.pdf> Acesso em: 20 maio 2012.

LOS MINEROS. Decisión anti sindical de Johnson Controls en Puebla, 22 mar. 12 [mensagem pessoal]. Mensagem recebida por < sotelocesar12@gmail.com> em: 22 mar. 2012.

MARTÍNEZ, Javier Puga. Cierra planta de Johnson Controls en Puebla y se va a Querétaro; el sindicato, el pretexto. La Jornada de Oriente, Puebla, 20 mar. 2012a. Disponível em: <http://www. lajornadadeoriente.com.mx/noticia/puebla/cierra-planta-de-johnson-controls-en-puebla-y-se-va-a-queretaro-el-sindicato-el-pretexto_id_5133.html> Acesso em: 27 maio 2012.

MARTínEZ, Javier Puga. Abogados del Centro de Apoyo al Trabajador huyen de Puebla por amenazas de muerte. La Jornada de Oriente. Puebla, 6 maio 2012b. Disponível em: <http://www. lajornadadeoriente.com.mx/noticia/puebla/abogados-del-centro-de-apoyo-al-trabajador-huyen-de-puebla-por-amenazas-de-muerte_id_8688.html> Acesso em: 29 jun. 2012.

ORGANIZAÇÃO INTERNACIONAL DO TRABALHO. Convenção n. 100 (sobre a igualdade de remuneração para a mão de obra masculina e feminina). 1951, Genebra. Disponível em: <http:// www.ilo.org/dyn/normlex/en/f?p=NORMLEXPUB:12100:3638074896939662::NO:12100:P12100_ ILO_CODE:C100:NO> Acesso em: 22 maio 2012.

PROYECTO DE DERECHOS ECONÓMICOS, SOCIALES Y CULTURALES; CENTRO DE APOYO AL TRABAJADOR. Urgent Action: Threats against Labor Rights Advocates in Puebla. Colonia Condesa, 2010. Disponível em: <http://www.prodesc.org.mx/wp-content/uploads/2010/12/URGENT_ACTION-CAT-21-DIC.pdf> Acesso em: 20 maio 2012.

Urgent action: new threats against labor rights advocates in Puebla. Colonia Condesa, 2011. Disponível em: <http://www.imfmetal.org/files/11011816211366/URGENT_ACTION_CAT_17_january_2011.pdf> Acesso em: 20 maio 2012.

RANGEL, Xóchitl. Cierra Johnson Controls planta en Puebla. El Universal. Puebla, 20 mar. 2012. Disponível em: <http://www.eluniversal.com.mx/notas/836915.html> Acesso em 27 maio 2012.

SOLIS, Valeska. Workers at Johnson Controlsin Puebla want to join miners' union. Federação Internacional de Trabalhadores da Indústria Metalúrgica. Genebra, 26 jan. 2010. Disponível em: <http://www.imfmetal.org/index.cfm?c=21915\&l=2> Acesso em: 20 out. 2011.

Cerca de 400 trabajadores quedarán sin trabajo por cierre de Johnson Controls Puebla. Federação Internacional de Trabalhadores da Indústria Metalúrgica, Genebra, 26 mar. 2012(a). Disponível em: <http://www.imfmetal.org/index.cfm?c=29438\&l=28> Acesso em: 27 maio 2012. Six years campaigning for justice for the Pasta de Conchos tragedy. Federação Internacional de Trabalhadores da Indústria Metalúrgica, Genebra, 21 fev. 2012(b). Disponível em: <http://www.imfmetal.org/index.cfm?c=28938\&l=2> Acesso em: 27 maio 2012.

Secuestran, golpean y amenazan de muerte a miembro del CAT en Puebla. Federação Internacional de Trabalhadores da Indústria Metalúrgica, Genebra, 17 maio 2012(c). Disponível em: <http://www.imfmetal.org/index.cfm?c=29957\&ol=28> Acesso em: 27 maio 2012.

UNITED AUTO WORKERS; MAQUILA SOLIDARITY NETWORK; INTERNATIONAL METALWORKERS FEDERATION; UNITED STATES LABOR EDUCATION IN THE AMERICAS PROJECT. The fight for an independent union at Johnson Controls, Puebla. Disponível em: <http://www.imfmetal. org/files/10050522043966/JCIProfile042210.pdf> Acesso em: 10 maio 2012. 
UNITED STATES LABOR EDUCATION IN THE AMERICAS PROJECT. Action alert: labor rights defenders assaulted in Puebla, Mexico. Disponível em: <http://salsa.democracyinaction.org/o/1618/p/ dia/action/public/?action_KEY=3666> Acesso em: 22 out. 2011.

UNITED STEELWORKERS; UNITED AUTO WORKERS; INTERNATIONAL METALWORKERS' FEDERATION; CANADIAN AUTO WORKERS; SINDICATO NACIONAL DE TRABAJADORES MINEROS, METALURGICOS, SIDERURGICOS, Y SIMILARES DE LA REPUBLICA MEXICANA. Carta conjunta ao vice-presidente da Johnson Controls. Milwaukee, WI, jan. 2011.

VIGEVANI, Tullo. MERCOSUL: impactos para trabalhadores e sindicatos. 1. ed. São Paulo: LTr, 1998.

\section{REFERÊNCIAS DE ENTREVISTAS}

GONZÁLES, Inés. Pesquisadora da Friedrich Ebert Stifung no México. Entrevista pessoal via Skype em $1^{\circ}$ jun. 2012.

MILLER, Suzanna. Responsável por projetos para o México na FITIM. Entrevista pessoal via Skype em 24 maio 2012. 